\title{
Understanding cement hydration by pair distribution function and rietveld analyses
}

Miguel A. G. Aranda ${ }^{1}$, Ana Cuesta ${ }^{1}$, Jesus D. Zea-Garcia ${ }^{2}$, Diana Londono-Zuluaga ${ }^{2}$, Isabel Santacruz ${ }^{2}$, Angeles G. De la Torre ${ }^{2}$

${ }^{1}$ ALBA Synchrotron, Barcelona, Spain, 2 Universidad de Malaga, Malaga, Spain

E-mail: migarcia@cells.es

There are many commercially important multiphase materials which contain amorphous/nanocrystalline phases, such as cement pastes, porcelains, or pharmaceutical compounds. The analysis of amorphous/nanocrystalline phase(s) within cement matrices that contain high amounts of crystalline phase(s) is very challenging. Synchrotron techniques can be very useful to characterize such complex samples [1]. Here, we report measurements of total scattering data quantitatively analyzed by Pair Distribution Function (PDF) and Rietveld methodologies to determine nanocrystalline and microcrystalline phase contents. Furthermore, laboratory techniques (laboratory powder diffraction using internal standard, thermal analysis, and magic-angle-spinning nuclear magnetic resonance) were also used to complement the sample characterization.

The main thrust of this work is to profit from the possibility to carry out total scattering PDF quantitative phase analyses in selected real-space ranges. This approach allows us to have a better insight about the nanocrystalline/microcrystalline components which coexist in cement pastes. These results were compared to those obtained by Rietveld quantitative phase analysis methodology. Following this approach, we have studied the hydration of two sets of reference samples, monocalcium aluminate, CaAl2O4, the main component of calcium aluminate cements, and tricalcium silicate, Ca3SiO5, the main component of Portland cements. At the studied temperatures, the hydration reactions are:

$3 \mathrm{CaAl} 2 \mathrm{O} 4(\mathrm{mc})+(12+4 \mathrm{n}) \mathrm{H} 2 \mathrm{O}(\mathrm{a}) \rightarrow \mathrm{Ca} 3 \mathrm{Al} 2(\mathrm{OH}) 12(\mathrm{mc})+4 \mathrm{Al}(\mathrm{OH}) 3 . \mathrm{nH} 2 \mathrm{O}(\mathrm{nc})$

$\mathrm{Ca} 3 \mathrm{SiO} 5(\mathrm{mc})+(1.3+\mathrm{n}) \mathrm{H} 2 \mathrm{O}(\mathrm{a}) \rightarrow 1.3 \mathrm{Ca}(\mathrm{OH}) 2(\mathrm{mc} \& \mathrm{nc})+(\mathrm{CaO}) 1.7(\mathrm{SiO} 2) \cdot \mathrm{nH} 2 \mathrm{O}(\mathrm{nc})$

Where 'mc' denotes microcrystalline, 'a' means amorphous and 'nc' stands for nanocrystalline.

For the CaAl2O4 study [2], and in addition to standard materials, CaAl2O4 was hydrated at $50{ }^{\circ} \mathrm{C}$ to yield 42 wt\% of microcrystalline hydrogarnet, $\mathrm{Ca} 3 \mathrm{Al} 2(\mathrm{OH}) 12,52$ wt\% of nanocrystalline aluminum hydroxide and additional minor contents of microcrystalline phases. The PDF analyses showed that the aluminum hydroxide gel has a gibbsite local structure with an average particle size close to $5 \mathrm{~nm}$. PDF and Rietveld quantitative phase analyses gave very consistent results. The attached figure shows experimental (blue circles), fitted (red solid line) and the difference curve (grey trace at the bottom of each panel) of PDF data for the CaAl2O4-hydrated sample in different real-space ranges.

Ca3SiO5 was hydrated at room temperature for 34 days, with different water-to-cement mass ratios to yield portlandite, $\mathrm{Ca}(\mathrm{OH}) 2$, and nanocrystalline C-S-H gel, with tobermorite local structure. About 10 wt\% of unreacted Ca3SiO5 remained in the hydrated samples. The local structure, particle size(s) and composition(s) of $\mathrm{C}-\mathrm{S}-\mathrm{H}$ and portlandite have been very recently studied by PDF [3]. We build on that publication for attaining further insights by using Rietveld and PDF analyses.

[1] Aranda, M. A. G. (2016) Cryst. Rev. 22, 150-196

[2] Cuesta, A. et al. (2017) Cem. Concr. Res. submitted

[3] Grangeon, S. et al. (2017) J. Appl. Cryst. 50, 14-21

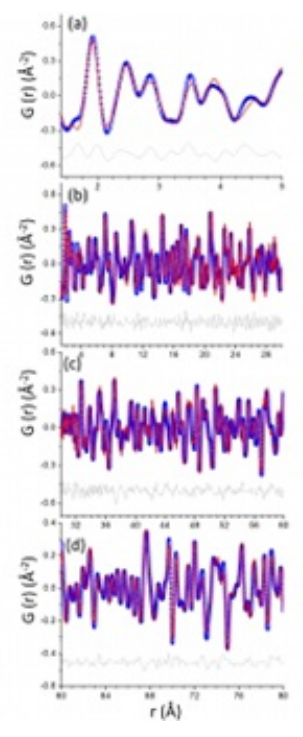

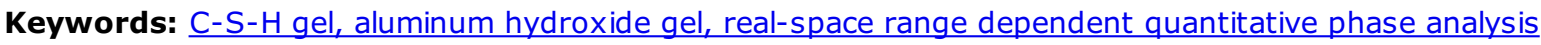

